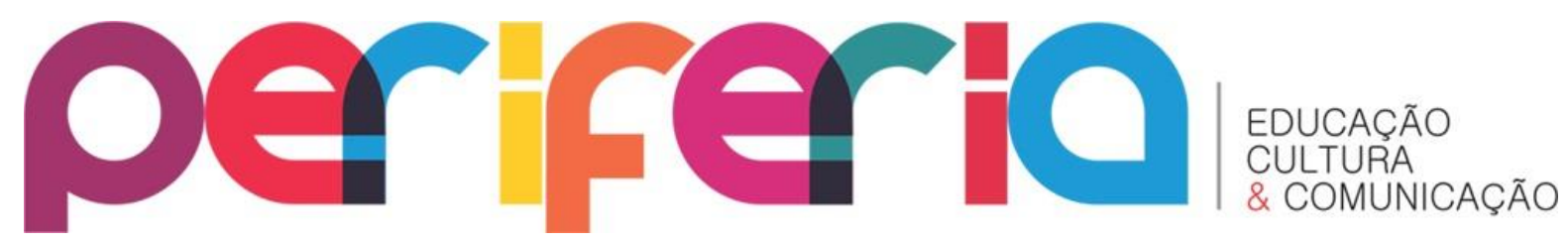

\title{
A PRODUÇÃO CULTURAL DA COMUNIDADE DISCIPLINAR DE ENSINO DE QUÍMICA
}

\author{
Rozana Gomes de Abreu ${ }^{1}$ \\ Universidade Federal do Rio de Janeiro
}

\section{RESUMO}

Este trabalho tem a finalidade de analisar como a comunidade disciplinar de ensino de Química estabelece uma identidade e uma cultura particular, e conseqüentemente um produto cultural. Com base nos discursos dos pesquisadores de ensino de Química, argumento que a comunidade disciplinar de ensino de Química funciona como uma comunidade de pensamento, a qual possui a "autoridade" para defender determinado conhecimento químico em um dado contexto sócio-histórico. Como comunidade de pensamento, ela autoriza e legitima as concepções e as relações nas quais está alicerçada constituindo valores, normas e visões de mundo que demarcam a sua identidade cultural. São os significados e os sentidos produzidos por essa comunidade de pensamento, associados aos processos de recontextualização e de hibridismo, que constituem uma produção cultural da comunidade disciplinar de ensino de Química.

Palavras-chave: ensino de química, identidade, cultura

\section{THE CULTURAL PRODUCTION OF THE DISCIPLINARY COMMUNITY OF EDUCATION CHEMISTRY}

\section{ABSTRACT}

This paper aims to analyze how the disciplinary community of education chemistry establishes an identity and a particular culture, and therefore a cultural product. I argue, based on the discourses of researchers education chemistry, that the disciplinary community of education chemistry is a thinking community, which has the "authority" to defend certain knowledge in a given socio-historical context. As a thinking community, it authorizes and legitimates the conceptions and relations which is based on forming values, norms and worldviews that demarcate their cultural identity. Are the significance and the senses produced by this thinking community, associates with the recontextualization and hybridism process, which constitute a cultural production community disciplinary of education Chemistry.

Keywords: education chemistry, identity, culture

\footnotetext{
${ }^{1}$ Professora do Colégio de Aplicação da UFRJ e pesquisadora nos grupos de pesquisa "Políticas de Currículo e Cultura", sob a coordenação da Prof.a Alice Lopes na UERJ, e "Processos de articulação e produção de sentidos nas políticas curriculares de formação de professores", sob a coordenação da Prof.a Rosanne Dias na UFRJ. E-mail: rgrozana@gmail.com
}

\section{v. 4 n. 1 jan-jul 2012}




\section{INTTRODUÇÃO}

Partindo da perspectiva de que vivemos em um mundo multicultural, entendo que todo indivíduo ou grupo social possui a sua identidade cultural em constante diálogo com as outras culturas. Imerso nessa perspectiva, considero o campo educacional um caldeirão cultural na medida em que grupos e indivíduos, totalmente diferentes entre si, trabalham trocando experiências e tecendo variadas relações, ressignificando concepções e construindo novas significações.

Nesse mundo, no qual a revolução tecnológica e científica vem transformando os modos de vida da sociedade bem como as formas de produção, circulação e apropriação do conhecimento, o campo educacional tenta lidar com essa pluralidade de identidades culturais, com a diversidade e com a diferença. A velocidade de informações, a demanda de um novo tipo de profissional, as relações entre sociedade e ciência, a multiplicidade de aparatos tecnológicos, entre as muitas questões presentes no momento atual, provocam um atravessamento das diversidades e das diferenças existentes, e geram uma inquietação constante tanto para alunos como para professores.

Candau (2006) aponta que é preciso o reconhecimento da própria identidade cultural, articulando a dimensão pessoal e coletiva, e identificando os processos de hibridação e de negociação, a fim de que se possa entender o mundo multicultural. A autora chama a atenção para a pouca consciência que temos dos processos sócioculturais e históricos na construção de nossas identidades bem como do cruzamento de outras culturas presentes nesses processos. Como, na maioria das vezes, não percebemos as diversas relações e articulações nas situações vividas bem como os seus desdobramentos sociais, culturais, históricos, políticos e econômicos.

Autores como Stuart Hall defendem que a cultura constitui-se um elemento de maior relevância para a compreensão das transformações que ocorrem hoje:

Por bem ou por mal, a cultura é agora um dos elementos dinâmicos - e mais imprevisíveis - da mudança histórica no novo milênio. Não deve nos surpreender, então, que as lutas pelo poder sejam, crescentemente, simbólicas e discursivas, ao invés de tomar, simplesmente, uma forma física e compulsiva, e que

Revista Periferia: Educação, Cultura \& Comunicação

v. 4 n. 1 jan-jul 2012 
as próprias políticas assumam progressivamente a feição de uma política cultural. (HALL, 1997, p. 97)

Nesse sentido, na medida em que a promoção das políticas educacionais nas últimas décadas assume uma ênfase particular para as ditas ciências exatas, a Biologia, a Química, a Física e a Matemática, pois os conhecimentos dessas áreas são considerados imprescindíveis para o desenvolvimento tecnológico e científico, a cultura desses campos curriculares também ganha destaque.

Logo, o estudo das identidades culturais dos campos disciplinares e dos processos que as constituem torna-se importante uma vez que podemos compreender melhor as articulações estabelecidas em função dessas mudanças do novo milênio. A pluralidade de questões a considerar e as diferenças existentes em cada campo disciplinar direcionam as ênfases e também os silenciamentos de cada área e, consequentemente, dos sujeitos que fazem parte dela. Por exemplo, a identidade cultural da comunidade disciplinar de ensino de Química é formada por diversas questões que perpassam o seu campo e os indivíduos pertencentes a ele, mas também é formada pelos inúmeros diálogos que estabelece com as culturas mais diversas, como a cultura popular, a cultura científica ou as culturas de outros conhecimentos.

Assim, a finalidade deste artigo é analisar como a comunidade disciplinar de ensino de Química configura a sua cultura escolar, como o conhecimento químico se constitui uma produção cultural na sociedade contemporânea e, consequentemente, uma política cultural.

\section{A CULTURA COMO PROCESSO SOCIAL E POLÍTICO}

Canclini (2005) comenta como a cultura pode ser vista como sinal de pertencimento e/ou como contraste (tendência antropológica); como algo que se adquire pela participação em algum contexto ou pela adesão de idéias (tendência sociológica); ou como ainda ter cultura é estar conectado (tendência dos estudos comunicacionais). A variedade de concepções constitui, segundo o autor, um labirinto de sentidos para o termo cultura.

\section{Revista Periferia: Educação, Cultura \& Comunicação}

\section{v. 4 n. 1 jan-jul 2012}


Segundo Morin (1981), a cultura é um corpo complexo de normas, símbolos, mitos e imagens que penetram o indivíduo em sua intimidade, estruturam os instintos, orientam as emoções. Para ele, os indivíduos se reconhecem como participantes dos símbolos, mitos, normas e códigos que a cultura lhe oferece, e ao mesmo tempo assumem a cultura como algo seu, como se todos os símbolos, mitos, normas e códigos fizessem parte da sua realidade interior (da sua natureza). Por isso, Morin destaca que a cultura trabalha sempre com duas dimensões, o real e o imaginário, os quais estão intimamente relacionados e irão constituir a subjetividade de cada indivíduo.

A variedade de conceitos é resultado dos diferentes direcionamentos teóricos que existem em nossa sociedade, que acabam influenciando na definição mais adequada para o termo cultura a ser utilizada em cada contexto. Não se pode esquecer que o contexto sócio-histórico assim como a história de vida dos indivíduos também influencia nesta escolha. Igualmente importante é reconhecer como as diversas concepções de cultura coexistem na sociedade, não excluindo umas às outras. Concordando com Canclini, não se pode apenas reconhecer as diferentes concepções de cultura, é preciso entender como essas diversas tendências se complementam e se desencontram. O entendimento sobre como as formas se configuram, se relacionam e estabelecem sentidos é importante, na medida em que podemos estabelecer relações com outros contextos. A compreensão é relevante porque as questões da cultura não estão isoladas, as questões culturais também são profundamente políticas e éticas, como diria Giroux (1999), bem como são econômicas e sociais.

Nesse processo a cultura apresenta-se como resultado de uma série de relações que estabelecem inúmeros significados e sentidos os quais podem se apresentar ora coerentes, ora contraditórios, ora frágeis. Argumento que o termo cultura deve ser pensado não como um todo uniforme, impenetrável e estático, mas sim como um conceito/espaço que é constituído e atravessado por outras visões e relações externas a ele, sempre em constante diálogo e mudança. 
Canclini (2005), partindo de concepções de Jean Baudrillard e Pierre Bourdieu, chega a uma definição de cultura com a qual tenho trabalhado:

Pode-se afirmar que a cultura abarca o conjunto de processos sociais de significação ou, de um modo mais complexo, a cultura abarca o conjunto de processos sociais de produção, circulação e consumo da significação na vida social. (CANCLINI, 2005, p. 41)

Esses processos sociais de significação englobam sujeitos, contextos e objetos, englobam as relações mais diversas e contraditórias, as questões sociais, econômicas, políticas e filosóficas. Logo, os significados produzidos pela cultura serão igualmente diversos e complexos, uma vez que a produção, a circulação e o consumo desses significados dependem da sua apropriação, reterritorialização e ressignificação pelos diferentes sujeitos e contextos.

Dessa forma, a cultura configura-se como uma "teia de significados" como defende Geertz (1989), como um sistema ou como uma rede interligada. Sendo uma rede, a cultura estabelece relações/vínculos com questões como poder, controle, economia, tecnologia, produção e mercado. Uma rede complexa e, portanto, delicada.

Nesse sentido, pensar a cultura como processo social de significação envolve compreendê-la também como um espaço de contestação, lutas e transformações (GIROUX, 1999) ou como "um espaço simbólico em que se articulam identidades em meio a interações, lutas e hostilidades constantes" (MACEDO, 2004, p. 127). Tal processo político baseia-se na busca pelo poder como também pelo reconhecimento social de seus significados.

Pensar na cultura como uma "teia de significados" e como espaço de lutas e contestações significa entender que ela é formada por relações/vínculos mais ou menos frágeis. A cultura não é estável ou imutável. Essa questão é destacada por Hall (2003) quando ele trata da desestabilidade da cultura. O autor afirma, em um sentido histórico amplo, que as culturas têm se tornado mais híbridas como resultado da globalização. As culturas deixam de serem doutrinas, muitas vezes consideradas como autossuficientes, fundamentais e superiores, para serem uma questão a mais,

\section{Revista Periferia: Educação, Cultura \& Comunicação}

\section{v. 4 n. 1 jan-jul 2012}


para fazerem parte de uma relação dialógica mais ampla com o "o outro". Os indivíduos recorrem aos vínculos, aos símbolos e às estruturas nas quais estão inseridos a fim de darem um sentido ao mundo, "sem serem rigorosamente atados a eles em cada detalhe de sua existência" (HALL, 2003, p. 74), configurando uma ação política específica.

Hall argumenta ainda, com base em Homi Bhabha, que o hibridismo configurase como um processo de tradução cultural, contínuo e inexcedível:

Não é simplesmente apropriação ou adaptação; é um processo através do qual se demanda das culturas uma revisão de seus próprios sistemas de referência, normas e valores, pelo distanciamento de suas regras habituais ou "inerentes" de transformação. Ambivalência e antagonismo acompanham cada ato de tradução cultural, pois o negociar com a "diferença do outro" revela uma insuficiência radical de nossos próprios sistemas de significado e significação. (BHABHA, apud HALL, 2003, p. 74-75).

Pode-se dizer que a cultura torna-se mais híbrida (mais diversa, mais complexa) na medida em que é constantemente atravessada por todas as questões que a influenciam. Por exemplo, a cultura científica não é determinada somente pelo conhecimento científico (produção, circulação e consumo), nem mesmo pela identidade da comunidade científica, ou até pelos aparatos que ajuda a desenvolver. A cultura científica é configurada também por questões econômicas, políticas ou filosóficas, fazendo com que os seus sistemas de referência, normas e valores sejam negociados continuamente, possibilitando os sentidos mais diversos.

Dessa forma, a cultura científica atual não pode ser entendida como a mesma do século passado, pois as questões que a constituem e a influenciam não são mais as mesmas. De modo semelhante, a cultura científica não é vista igualmente por diferentes grupos, como é o caso das diferentes comunidades disciplinares em ensino, pois não compartilham os mesmos símbolos, normas e finalidades. No entanto, essas diferentes concepções ou visões dialogam e negociam continuamente estabelecendo os mais variados sentidos.

Revista Periferia: Educação, Cultura \& Comunicação

v. 4 n. 1 jan-jul 2012 
Canclini argumenta que "um dos méritos da hibridação é ela minar as formas binárias de pensar a diferença" (CANCLINI, 2003, p. 114), uma vez que a diferença sempre se estabelece em função do outro e que o hibridismo negocia um processo cultural de uma diferença que desliza permanentemente dentro da outra. Dessa forma, nenhum grupo ou nenhuma cultura permanece mais dentro dos seus limites, o que reforça a idéia da cultura como uma "teia de significados".

A articulação dos diferentes culturais, superando as suas identidades e seus discursos originais e/ou iniciais, fornecem os entre-lugares, os espaços necessários para a produção de novas identidades, de novos significados e de novos sentidos, sejam eles consentidores ou contestadores. Segundo Dussel (2002), a hibridação opera articulando modelos internos e externos bem como articula também as diferentes tradições e discursos, criando assim novos sentidos para as novas equivalências.

Em outras palavras, o caráter híbrido da cultura pode ser entendido como resultado de um duplo processo: primeiro, do processo de deslocamento de questões e relações de origem (no caso de concepções, valores, símbolos, normas) de determinado contexto ou campo, e segundo, do processo de recolocação e ressignificação dessas em outras questões e relações.

Esse duplo processo, de deslocamento e de recolocação e ressignificação, produz sentidos diversos os quais estarão sujeitos aos processos de interpretação e de lutas, podendo ser comparados aos processos de recontextualização de Bernstein (1996). Esse pesquisador afirma que quando um texto é apropriado, ele, em geral, sofre uma transformação antes de sua recolocação, na medida em que foi retirado de seu local original, selecionado, simplificado, condensado e elaborado sendo por fim reposicionado em um novo local e refocalizado. Nesse processo, o texto não é mais o mesmo, pois os sentidos e as articulações são novos.

Com base nessas considerações, argumento que as comunidades disciplinares, por intermédio dos pesquisadores em ensino e dos professores das disciplinas escolares, atuam difundindo discursos e visões de mundo, o que contribui para a construção da identidade da comunidade disciplinar de ensino. Tais discursos

\section{Revista Periferia: Educação, Cultura \& Comunicação}

v. 4 n. 1 jan-jul 2012 
e visões são apropriados, recontextualizados e associados a outros discursos e contextos, de acordo com os interesses e as finalidades do contexto sócio-histórico em questão, constituindo uma rede de significados ampla e complexa bem como uma política cultural específica.

É preciso ressaltar que a comunidade disciplinar, tal como a disciplina escolar, não é apenas uma subdivisão do conhecimento, mas uma construção sóciohistórica que associa tradições de pensamento, práticas organizadas, visões de mundo, discursos e sujeitos, visando ao atendimento de determinadas finalidades sociais (GOODSON, 1997, 1999). Dessa forma, a comunidade disciplinar de ensino distribui, pelas suas práticas e propostas curriculares, determinadas concepções e consensos que influenciarão tanto os professores disciplinares quanto os discursos sociais mais diversos.

A investigação e a análise da produção de políticas no contexto disciplinar, em qualquer disciplina, devem levar em consideração a complexidade de relações e interesses que se constituem na sua construção. Os indivíduos pertencentes a um determinado grupo disciplinar participam de outros contextos, estabelecendo diálogo como os discursos mais diversos. Assim, a produção de políticas pelo contexto disciplinar não envolve somente a comunidade disciplinar em questão, mas também toda a rede de relações que influenciam na produção de significados por essa comunidade (ABREU, 2010).

Dessa forma, a compreensão de uma determinada cultura disciplinar deve levar em consideração todas as questões até aqui traçadas. Defendo que a cultura do conhecimento químico corresponde a um processo histórico e social, o qual articula discursos, valores, normas e símbolos circulantes em vários campos da sociedade. Uma cultura que está sujeita à recontextualização e ao hibridismo, que é ao mesmo tempo um espaço de contestação e transformação como também um espaço de pertencimento.

Revista Periferia: Educação, Cultura \& Comunicação

v. 4 n. 1 jan-jul 2012 


\section{O CAMPO DE ENSINO DE QUÍMICA}

Como mencionado anteriormente, entender a cultura de um determinado grupo envolve compreender não só os valores, normas, discursos e história dos sujeitos e do contexto que o constitui. É preciso entender como essas questões sofrem influência de outros contextos e sujeitos, estabelecendo relações por vezes delicadas.

Nesse sentido, ao propor neste artigo investigar como o campo de ensino de Química tem configurado uma cultura do que é o conhecimento químico e como atua na produção de políticas para a escola, preciso situar, mesmo que parcialmente, o contexto e os sujeitos desse campo assim como o contexto sócio-histórico e os diversos discursos que o atravessam e o interpenetram.

O campo de ensino de Química teve início com a criação do Departamento de Química, em 1934, na Faculdade de Filosofia, Ciências e Letras da Universidade de São Paulo. Entretanto, somente a partir de 1978, por ocasião da 1a Reunião Anual da Sociedade Brasileira de Química (SBQ), houve uma significativa mudança /valorização desse campo de modo que "abrisse um espaço na comunidade química para estudos e pesquisas em ensino de química" (SCHNETZLER, 2002, p. 17). Tal valorização foi marcada pelas crescentes pesquisas em ensino de Química entre as décadas de 60 e 80 , resultado das reflexões e das críticas aos movimentos de reformas curriculares ocorridos no mesmo período. Algumas das bases desses movimentos consistiam na visão empirista da ciência, na ênfase do uso do laboratório para a introdução e exploração de problemas utilizando uma abordagem quantitativa e estatística dos resultados, na ênfase em estudos de caso com abordagem qualitativa, em contribuições da psicologia cognitivista e nos processos de aprendizagem, no papel da linguagem na construção de conceitos e na mudança conceitual.

Dez anos mais tarde (1988) era criada a Divisão de Ensino na Sociedade Brasileira de Química, fruto da crescente discussão sobre o ensino de Química nos diversos encontros da área. Também foi em um desses encontros que surgiu a proposta de criar uma revista que pudesse "subsidiar o trabalho, a formação e a 
atualização de professores e professoras e ainda suscitar debates e reflexões sobre o processo de ensino e aprendizagem de química" (QNEsc, 1995, p. 2).

Assim, em maio de 1995 era lançada a revista Química Nova na Escola, um projeto financiado pelo Sub-Programa para a Educação em Ciências (SPEC) do PADCTCAPES. Tal iniciativa foi importante, conforme ressalta Mortimer, na medida em que "ajudou a criar e consolidar uma comunidade brasileira de Educação em Ciências" (MORTIMER, 2004, p. 4).

O rápido panorama aqui traçado mostra que o campo de ensino de Química é relativamente novo, considerando que as discussões e as idéias sobre o ensino de Química avançaram bem em trinta anos. Apresenta também em que marco sóciohistórico está inserido, possibilitando entender as inúmeras relações e discursos que perpassam esse campo disciplinar.

Com relação aos sujeitos-atores que constituem o campo de ensino de Química, Schnetzler destaca o número reduzido de pesquisadores nessa área. Segundo a autora, em pesquisa realizada de 1971 a 2001, em várias universidades brasileiras, existiam 77 mestres e 32 doutores em educação química. No entanto, no ano de 2002, apenas 13 doutores estavam envolvidos com a orientação e formação de professores.

Esse quadro expressa como as discussões sobre o ensino de Química são restritas também pelo pequeno número de pesquisadores-formadores os quais são de extrema importância para o desenvolvimento da área, na medida em que são formadores de opinião, em que estabelecem relações em contextos diversos, criam e recriam os códigos, as normas e os rituais peculiares do campo disciplinar, produzindo com isso inúmeros sentidos na sociedade.

Apesar de a área disciplinar ser relativamente nova, se comparada com outros campos disciplinares de ensino, e com um pequeno número de pesquisadores, ela consegue configurar e defender a cultura do que é o conhecimento químico.

Argumento que a comunidade disciplinar de ensino de Química funciona como uma comunidade de pensamento, a qual tem o poder de impor discursos e visões de mundo particulares na sociedade (ANTONÍADES, 2003). Em outras palavras, é a

\section{Revista Periferia: Educação, Cultura \& Comunicação}

\section{v. 4 n. 1 jan-jul 2012}


comunidade disciplinar de ensino de Química que possui a "autoridade" para defender determinado conhecimento químico em um dado contexto sócio-histórico. Entretanto, não se pode esquecer que esses discursos e visões de mundo, "autorizados" e legitimados pela comunidade disciplinar de ensino, estabelecerão diversas relações em cada contexto, o que pode promover o reforço de suas ideias ou a criação de novos discursos e visões, combinados ou não. Essa comunidade de pensamento constitui a identidade cultural do campo disciplinar de ensino estabelecendo um conjunto de processos de significação nos contextos mais diversos.

Os discursos, valores, normas, símbolos, tradições do campo de ensino de Química, autorizados e legitimados, contribuem para a configuração do conhecimento químico como produto cultural. Para entender como o campo de ensino de Química constitui e configura uma identidade e uma cultura particular, na próxima seção finalizo analisando os discursos circulantes sobre o conhecimento químico e como esses discursos colaboram na construção da identidade cultural da comunidade e na produção de discursos sobre sua cultura.

\section{CONHECIMENTO QUÍMICO E PRODUÇÃO CULTURAL: TECENDO CONSIDERAÇÕES}

A identidade do campo disciplinar de Química ou do conhecimento químico é associada muitas vezes à figura do cientista maluco ou de algo contrário à natureza, como algo preciso, comprovado experimentalmente, logo, verdadeiro e neutro. Essas associações trabalham com os dois aspectos de cultura que Morin destaca: o real e o imaginário. Sabemos que a figura do cientista não representa a identidade do campo disciplinar de ensino de Química, mas ela está fortemente presente no imaginário social; que o conhecimento químico pode estar relacionado à construção e à reconstrução da natureza, e não só com questões nocivas à natureza. Sabemos que o conhecimento químico não é um objeto natural e inquestionável, ao contrário, o conhecimento químico é fruto de uma construção humana coletiva, a qual permite legitimar seus saberes e intenções perante a sociedade, não sendo isentos de neutralidade nem obrigatoriamente verdadeiros e definitivos.

\section{Revista Periferia: Educação, Cultura \& Comunicação}

\section{v. 4 n. 1 jan-jul 2012}


Nessa perspectiva, o entendimento do conhecimento químico como produto cultural se configura pela produção de diferentes significados nos variados contextos por onde transita e estabelece ligações. A rede de significados produzida pelo conhecimento químico necessita dialogar e negociar com outros produtos culturais (outros conhecimentos, outros contextos) como forma de se diferenciar, valorizar e legitimar na sociedade.

Assim, a defesa do conhecimento químico adquire um sentido a mais para a comunidade disciplinar. É preciso ensinar e difundir o conhecimento químico como forma de legitimar e autorizar as concepções e as relações em que a comunidade disciplinar está alicerçada, como forma de demarcar a sua identidade cultural.

A associação do conhecimento químico com as questões sociais é um dos argumentos mais utilizados pela comunidade disciplinar nessa direção. Vários pesquisadores em ensino de Química chamam a atenção para a diferente leitura do mundo possibilitada às pessoas pelo conhecimento químico (CHASSOT, 1995; MALDANER, 1995; SANTOS \& SCHNETZLER, 2000). A defesa consiste no fato de que o conhecimento químico é um facilitador da leitura do mundo na medida em que "permite que os indivíduos integrem-se à sociedade de forma mais ativa e consciente" (MALDANER, 1995, p. 15). Chassot argumenta que é preciso "formar cidadãos que não só saibam ler melhor o mundo onde estão inseridos, como também, e principalmente, sejam capazes de transformar este mundo para melhor" (1995, p. 45).

Ressaltam ainda que para ser um facilitador da leitura do mundo, o conhecimento químico deve rejeitar o rótulo de conhecimento asséptico, dogmático, abstrato, a-histórico e ferreteador. É necessário que o conhecimento químico esteja cada vez mais próximo da realidade dos alunos e dos professores, configurando uma situação mais concreta. Para isso é importante que se trabalhe com os significados considerados reais e imaginários do que é considerado como conhecimento químico atualmente bem como as suas inter-relações.

A comunidade disciplinar também não nega que o desenvolvimento e o avanço tecnológico estabelece uma dependência cada vez maior com relação a esse 
tipo de conhecimento. Dependência essa que vai desde a utilização de produtos químicos até às inúmeras influências e impactos em diversos setores da sociedade, como por exemplo, os empregos e os efeitos das aplicações tecnológicas. Por esses motivos, Santos \& Schnetlzer (2000, p. 47-48) defendem que:

[...] é necessário que os cidadãos conheçam como utilizar as substâncias no seu dia-a-dia, bem como se posicionem criticamente com relação aos efeitos ambientais da química e quanto às decisões referentes aos investimentos nessa área, a fim de buscar soluções para os problemas sociais que podem ser resolvidos com a ajuda do seu desenvolvimento.

Os pesquisadores em ensino de Química concordam que não é preciso ter conhecimentos específicos de Química para que um indivíduo viva melhor na sociedade. No entanto, argumentam que o conhecimento químico é relevante para o exercício consciente da cidadania. Ciscato \& Beltran apontam a importância de a aprendizagem de Química ser relacionada às necessidades da sociedade atual:

Ter noções básicas de química instrumentaliza o cidadão para que ele possa saber exigir os benefícios da aplicação do conhecimento químico para toda a sociedade. Dispor de rudimentos dessa matéria ajuda o cidadão a se posicionar em relação a inúmeros problemas da vida moderna, como poluição, recursos energéticos, reservas minerais, uso de matérias-primas, fabricação e uso de inseticidas, pesticidas, adubos e agrotóxicos, fabricação de explosivos, fabricação e uso de medicamentos, importação de tecnologia e muitos outros. (apud SANTOS \& SCHNETLZER, 2000, p. 53)

Santos (1996) ressalta que a formação do cidadão não envolve apenas o ensino dos conceitos químicos, mas também os aspectos sociais, políticos e econômicos. A articulação do conhecimento químico com esses aspectos permite a formação de um cidadão mais ativo capaz de reconhecer as interações existentes nas situações vividas bem como de interferir ou transformar a sua realidade.

Tais concepções apresentam influências de um movimento de ordem mundial denominado Ciência, Tecnologia e Sociedade (CTS), o qual valoriza a educação científica do cidadão preparando-o para tomar decisões com relação aos aspectos 
científicos e tecnológicos assim como para provocar mudanças sociais na busca de uma melhor qualidade de vida.

Essas reflexões do campo de ensino de Química não são exclusivas da área, elas estão presentes em diversos outros campos. Na verdade, a valorização da educação científica decorre do avanço explosivo do conhecimento em todos os campos da ciência e das mudanças sociais, políticas e econômicas que afetam a sociedade moderna e pós-moderna.

O reforço pelo conhecimento químico mais significativo, em constante diálogo com a ciência e a tecnologia, capaz de formar o cidadão para a compreensão e o uso das informações químicas e para a tomada de decisões no contexto social no qual está inserido determina uma identidade específica. O conhecimento químico não pode se restringir à lógica interna da disciplina valorizando exclusivamente as teorias e fatos químicos, mas sim deve reelaborar o seu conhecimento relacionando-o a temas sociais relevantes. Em outras palavras, um conhecimento químico mais significativo proporciona um contínuo diálogo entre a sua cultura e as demais, principalmente a científica e a tecnológica.

Os discursos curriculares dos pesquisadores em ensino de Química colaboram para a constituição de uma política cultural da sua comunidade disciplinar na medida em que visam orientar determinadas significações simbólicas e obter consenso para uma determinada questão e/ou para uma transformação social compartilhada por seus pares. Tal política cultural é constituída pelos processos sociais de significação nos projetos de formação continuada, nos trabalhos de congressos, na elaboração de revistas e livros didáticos, na elaboração de propostas curriculares (oficiais ou não), dentre outros contextos. Apesar da existência de um pequeno número de pesquisadores-formadores em ensino de Química, eles atuam intensamente na construção dos significados e dos sentidos que circulam no campo disciplinar e na sociedade uma vez que participam de diversas atividades que constituem a política cultural da comunidade disciplinar de ensino de Química.

A produção cultural pela comunidade disciplinar de ensino de Química acontece por intermédio de articulações entre o conhecimento químico, o 
conhecimento científico e tecnológico moderno, e por questões ligadas à melhoria da qualidade de vida. O conhecimento químico se hibridiza na medida em que estabelece essas articulações a fim de buscar um sentido, uma finalidade para a constituição e manutenção de sua identidade cultural. Essas articulações promovem um lugar de destaque nos debates sociais mais diversos atualmente e acaba fortalecendo o discurso de que a melhoria na qualidade de vida neste século advém do desenvolvimento do conhecimento químico. Destaque esse que se converte em programas nacionais de incentivo à ciência, à cultura e à tecnologia. Tal processo conduz a uma afirmação tanto da importância do conhecimento químico quanto da comunidade disciplinar de ensino de Química. Não se pode esquecer que essa afirmação e esse reconhecimento aumentam o prestígio e o poder conferido a este campo disciplinar os quais serão utilizados na luta por mais espaço, mais investimentos e mais status em todos os setores da sociedade em que circula.

Nesse sentido, afirmo que os sentidos produzidos nessas relações e articulações promovem o consumo e a circulação do pensamento disciplinar químico na sociedade, como também constituem uma política cultural específica para essa comunidade disciplinar de ensino.

Ressalto ainda, que essas articulações constituem-se como processos híbridos, negociados continuamente em uma sociedade em constante mudança. Articulações complexas e extremamente delicadas para a comunidade disciplinar de ensino de Química que tenta não cair na questão do ornamento cultural, no qual o conhecimento químico serviria apenas para que os indivíduos fossem chamados de letrados em ciências, nem na questão da supervalorização científica, no qual o conhecimento químico teria um fim em si mesmo. Por isso, o melhor caminho encontrado nos últimos anos pela comunidade disciplinar de ensino de Química tem sido o de associar o conhecimento específico a questões sociais, a questões em que o cidadão possa usar o seu conhecimento para julgar ou formar opinião, pois desta maneira sua cultura consegue se aproximar e articular com diferentes discursos sociais, legitimando a identidade da comunidade disciplinar de ensino na "sociedade do conhecimento".

Revista Periferia: Educação, Cultura \& Comunicação

v. 4 n. 1 jan-jul 2012 


\section{REFERÊNCIAS BIBLIOGRÁFICAS}

ABREU, Rozana Gomes de. A comunidade disciplinar de ensino de Química na produção de políticas curriculares para o ensino médio no Brasil. 2010. 207p. Tese (Doutorado) Faculdade de Educação, Universidade do Estado do Rio de Janeiro, Rio de Janeiro, 2010.

ANTONÍADES, Andreas. Epistemic Communities, Epistemes and the Construction of (World) Politics. Global Society: Journal of Interdisciplinary International Relations. vol. 17, $n^{\circ} 1, \mathrm{p} .21-$ 38, jan, 2003.

BERNSTEIN, Basil. A estruturação do discurso pedagógico: classe, códigos e controle. Petrópolis: Vozes, 1996.

CANCLINI, Néstor García. A globalização imaginada. São Paulo: lluminuras, 2003.

interculturalidade. Rio de Janeiro: Ed. UFRJ, 2005.

Diferentes, desiguais $e$ desconectados: mapas da CANDAU, Vera Maria. O/A educador/a como agente cultural. In: LOPES, A. R. C.; MACEDO, E. F. de \& ALVES, M. P. C. (orgs.). Cultura e política de currículo. Araraquara: Junqueira \& Marin, 2006.

CHASSOT, Attico Inacio. Catalisando transformações na educação. 3a ed. Ijuí: Unijuí, 1995.

DUSSEL, Inês. O currículo híbrido: domesticação ou pluralização das diferenças. In: LOPES, A. C. \& MACEDO, E. (orgs). Currículo: debates contemporâneos. São Paulo: Cortez, 2002.

GEERTZ, Clifford. A interpretação das culturas. Rio de Janeiro: Livros Técnicos e Científicos, 1989.

GIROUX, Henry A. Cruzando as fronteiras do discurso educacional: novas políticas em educação. Porto Alegre: Artes Médicas, 1999.

GOODSON, Ivor F. A construção social do currículo. Lisboa: Educa, 1997. . Currículo: teoria e história. 3a ed. Petrópolis: Vozes, 1999.

HALL, Stuart. A centralidade da cultura: notas sobre as revoluções culturais do nosso tempo. Educação e Realidade, Porto Alegre: UFRGS, v. 22, n. 2, p. 15-46, 1997.

Da diáspora: identidades e mediações culturais. Belo Horizonte: Ed. UFMG,

2003.

MACEDO, Elizabeth. Ciência, tecnologia e desenvolvimento: uma visão cultural do currículo de ciências. In: LOPES, A. C. \& MACEDO, E. (orgs). Currículo de ciências em debate. Campinas: Papirus, 2004.

MALDANER, Otavio Aloísio \& PIEDADE, Maria do Carmo Tocci. Repensando a Química. Química Nova na Escola. no 1, p. 15-19, 1995.

MORIN, Edgard. Cultura de massa no século XX. Rio de Janeiro: Forense Universitária, 1981. MORTIMER, Eduardo Fleury. Dez anos de Química Nova na Escola: a consolidação de um projeto da divisão de ensino da SBQ. Química Nova na Escola, no 20, p. 3-10, 2004.

QNEsc. Química Nova na Escola, no 1, 1995.

SANTOS, Wildson Luiz Pereira dos. Como educar o cidadão por meio da Química. Caderno de Resumos e Anais do VIII ENEQ / VIII ECODEQ: A Química e a formação do cidadão. Campo Grande: UFMS, p. 19-27, julho, 1996.

SANTOS, Wildson Luiz Pereira dos \& SCHNETZLER, Roseli Pacheco. Educação em Química: compromisso com a cidadania. 2a ed. ljuí: Unijuí, 2000.

SCHNETZLER, Roseli Pacheco. A pesquisa em ensino de Química no Brasil: conquistas e perspectivas. Química Nova. Vol. 25, Supl. 1, p. 14-24, 2002.

Revista Periferia: Educação, Cultura \& Comunicação

v. 4 n. 1 jan-jul 2012 